\title{
MOMENTUM AND MEAN REVERSION IN REGIONAL HOUSING MARKETS: EVIDENCE FROM VARIANCE RATIO TESTS
}

\author{
Elias OIKARINEN a,*, Felix SCHINDLER b \\ a Department of Economics, University of Turku, Rehtorinpellonkatu 3, 20500 Turku, Finland \\ ${ }^{b}$ Center for Real Estate Studies, Steinbeis University Berlin, Eisenbahnstrasse 56, D-79098 Freiburg \\ im Breisgau, Germany
}

Received 4 April 2014; accepted 8 July 2014

\begin{abstract}
We study the persistence and reversion patterns of housing price growth by computing variance ratios applying Kim's (2006) Wild bootstrapping and using Finnish data for the period 1987-2010. The momentum effect in housing price growth is found to be long-lasting and substantially greater in size than the eventual reversion. The results indicate that high-order autocorrelations are important concerning the long-horizon attractiveness of housing investments and that housing is a notably riskier asset in the long term than suggested by conventional portfolio analysis. The analysis further shows that the dynamics vary across regional housing markets and across dwelling types. The findings have important implications for investors, credit institutions, and policy makers.
\end{abstract}

KEYWORDS: Housing prices; Momentum; Mean reversion; Variance ratio; Portfolio allocation

\section{INTRODUCTION}

The classic results of Samuelson (1969) and Merton (1969) show that if asset returns are independently and identically distributed (i.i.d.), an investor with a power utility function who rebalances her portfolio optimally should choose the same asset allocation regardless of her investment horizon. However, it has been known for a long time that housing price movements exhibit notable predictability. Importantly, more recent research has shown that predictability in asset returns may lead to strong horizon effects (e.g. Barberis 2000; Lynch, Balduzzi 2000; Campbell, Viceira 2002). In particular, due to mean aversion and mean reversion in asset prices, the relative riskiness of various assets and thereby the optimal portfolio allocation are dependent on the planned investment horizon.

Mean aversion, or "momentum", implies that high (low) returns today predict high (low) returns in the relatively close future as well. Mean reversion, instead, indicates just the opposite. As greater momentum induces more volatile long-

* Corresponding author. E-mail: elias.oikarinen@utu.fi term returns, mean-averting assets are less attractive for a long-term investor than suggested by the conventionally used short-run volatility measures.

In this study, "momentum" refers to time series momentum that is related to, but different from, the typical meaning of "momentum" in the finance literature. While the momentum literature focuses on the relative performance of assets in the cross-section, time series momentum focuses purely on individual asset's time series properties (Moskowitz et al. 2012). The early research on the time series properties of asset returns (e.g. De Bondt et al. 1985; Fama, French 1988; Poterba, Summers 1988) concentrates on financial assets. Much of the empirical evidence suggests that even the financial asset returns are not i.i.d. Pioneering work regarding the housing market was conducted by Case and Shiller $(1989,1990)$. The results by Case and Shiller (1989, 1990), which implied the existence of notable short-run persistence in housing price growth and showed somewhat weaker evidence of longer-horizon negative serial correlation, have been confirmed by numerous studies more recently. 
The planned holding period of direct real estate investments is generally long due to the typical characteristics of direct real estate assets, such as relatively low liquidity and high transaction costs. Collett et al. (2003) find the median realized holding period for institutional real estate investors to be generally between 7 and 14 years. Hence, the horizon effects caused by the time series properties of asset returns are outstandingly relevant to investors holding direct real estate assets in their portfolios. Nevertheless, the empirical literature regarding the mean reversion and aversion of housing returns typically studies horizons up to a couple of years at maximum. Moreover, the magnitude and length of momentum and subsequent reversion may well vary across regional housing markets and between dwelling types. The potential regional differences in the horizon effect can have notable portfolio implications. Therefore, more research on the long-horizon characteristics of housing returns is needed.

This paper provides new empirical evidence on the momentum and reversion patterns of housing returns, and their variation across regions. Similar to the recent studies by MacKinnon and $\mathrm{Al}$ Zaman (2009) and Rehring (2012), we investigate the horizon effects up to investment horizons that are typical for direct real estate investments. While most previous related studies employ econometric models to investigate the persistence in real estate price movements and cater for relatively shortterm autocorrelation dynamics only (Case, Shiller 1989, 1990; Englund, Ioannides 1997; Capozza et al. 2004; MacKinnon, Al Zaman 2009; Rehring 2012), this study examines the horizon effects by computing variance ratio statistics that account for autocorrelations up to 40 quarters. The computed variance ratios essentially summarize the autocorrelation patterns and thereby cater for the potential serial correlation in housing price movements for the whole ten-year lag length, and enable a detailed examination of the shapes and durations of momentum and mean reversion as well as allow easily for comparison between markets.

Given the considerable frictions in the housing market and the observed highly sluggish adjustment of housing prices to various shocks, it can be important to consider the high-order autocorrelations when investigating the horizon effects. There are three previous articles (Gu 2002; Schindler $2013,2014)$ that report variance ratio statistics for housing prices in the U.S. market or the U.K. market, but these studies account for autocorrelations up to four years at maximum.
The empirical analysis uses quarterly data for the period 1987-2010 for Finland. Finland provides an interesting case study, since the market has shown prominent price cycles during the sample period, and the country is relatively small and culturally and economically coherent. Given that the number of time series observations is relatively small, the Wild bootstrap approach of Kim (2006) is used to compute the variance ratio statistics and their confidence intervals. This appears to be the first study on real estate returns using the bootstrapping approach. As a robustness check, we also use runs tests to test for non-parametric persistence in housing prices. The findings from the runs test are in line with those from variance ratio analysis.

As expected, the results show that housing prices do not follow a random walk in any of the studied housing markets. Instead, momentum in housing returns is long-lasting and considerable in size. In the Finnish regional markets, the variance ratios peak at the 4 to 5 year horizon after which mean reversion starts. The reversion is substantially weaker than the initial mean aversion. The observed momentum and reversion patterns are consistent with sentiment theories of initial underreaction and delayed over-reaction of investors.

The empirical observations entail several practical implications. First, housing is a notably riskier asset in the long term than suggested by variances computed from quarterly price movements. Second, since the stock and bond returns do not exhibit similar strong momentum as returns for housing, the relative attractiveness of housing investments is weaker for a long-horizon investor than suggested by the conventional portfolio analyses that employ short-term variances and assume i.i.d. returns. The results also show that the horizon effect can substantially vary across regions and between dwelling types. These differences influence the optimal housing portfolio allocation and highlight one more reason why it is problematic to use country level housing price data when analyzing the optimal portfolio allocation or housing price dynamics. Finally, the observed time series patterns imply that housing prices are predictable even in the long horizon.

Interestingly, the observed length and size of momentum are substantially greater than those reported recently in studies using Vector Autoregressive (VAR) model based computations. The VAR models, which rely on the approach introduced by Campbell and Viceira (2005), do not account for potential high-order autocorrelations thereby 
assuming that a relatively short lag length can capture the autocorrelation dynamics. Our findings suggest that higher-order autocorrelations are likely to be relevant regarding the extent of actual horizon effects.

The paper proceeds as follows. The next section reviews empirical findings on housing market momentum and mean reversion, and discusses the potential theoretical explanations for the empirical findings. The third section presents the data used in the empirical analysis, while section four delineates the methodological approach. The empirical variance ratio analysis and runs tests are conducted in section five after which the study is concluded.

\section{THEORETICAL CONSIDERATIONS AND PREVIOUS EMPIRICAL FINDINGS}

Short-run persistence and long-run mean reversion in housing price growth has aroused great interest since the empirical findings of Case and Shiller (1989, 1990). The result of Case and Shiller (1989), which implied the existence of notable persistence in housing price growth, has been confirmed by numerous studies since that (e.g. Englund, Ioannides 1997; Capozza et al. 2004; Røed Larsen, Weum 2008; Beracha, Skiba 2011). Similarly, a number of empirical examinations (e.g. Capozza, Seguin 1996; Englund, Ioannides 1997; Meen 2002; Capozza et al. 2004; Glaeser, Gyourko 2007) support the findings of Case and Shiller (1990) that showed evidence of longer-horizon negative serial correlation in housing price changes. Generally, these investigations look at short horizons compared with the actual holding periods of direct real estate investments.

The more recent studies by MacKinnon and Al Zaman (2009) and Rehring (2012) use the Campbell and Viceira (2005) type of VAR models to investigate the direct real estate momentum and reversion patterns at long horizons. These VAR models assume that a relatively short lag length can capture the autocorrelation dynamics, and do not account for potential high-order autocorrelations. According to MacKinnon and Al Zaman (2009), returns to direct real estate in the U.S. exhibit momentum only up to a couple of quarters after which the returns are mean reverting. Due to the strong mean reversion, real estate returns appear to be less volatile in the long horizon than in the short run. Similarly, Rehring (2012) finds that real estate returns exhibit notably greater long-term reversion than initial short- term momentum in the U.K. In that study, the use of an unsmoothed appraisal-based index that does not show notable autocorrelation in housing price growth is potentially problematic, as transactionbased data that do not exhibit appraisal smoothing have constantly indicated that housing prices are highly autocorrelated.

According to the conventional rational expectations stock-flow model of housing markets, after a shock in the fundamentals housing prices overshoot first because of the inability of the housing stock to respond immediately, i.e., because of the construction lag. After the single overshot, the price level gradually adjusts towards its new longrun level, i.e., mean reverts, as the housing supply responds to the changed housing price level. This theory suggests that the price level peaks immediately after the shock so that short-run mean aversion does not take place. At longer lags, autocorrelations should be close to zero if the adjustment process is reasonably fast.

Glaeser and Gyourko (2007) introduce a model where mean reversion is not only a result of the construction lag, but also of the mean reversion in economic shocks to local productivity. While this model is not able to explain the shorter-term mean-averting tendency, the liquidity constraints faced by households together with the positive interaction between housing prices and credit availability may create self-re-enforcing cycles that cause mean-averting housing prices in the relatively short term (Goodhart, Hofmann 2007; Oikarinen 2009a, 2009b).

Several studies show that housing price growth is predictable by previous housing price movements even when fundamental variables are included in the estimated model (e.g. Case, Shiller 1990; Capozza et al. 2004). Some of these estimations also include credit variables that are likely to cater for the interaction between credit and housing prices (Oikarinen 2009a, 2009b). These results suggest that the short-run persistence in housing price growth cannot be wholly explained by the short-term persistence in economic fundamentals or the interaction between credit availability and housing prices. However, irrational features are not necessary to explain even this finding. Given the heterogeneous product, time-consuming search processes, and other frictions in the housing market, rapid price adjustments may not be rational (DiPasquale, Wheaton 1994).

In addition to the rational expectations considerations, the literature presents several potential behavioral features that may cause short-horizon 
persistence in housing price growth ${ }^{1}$. In particular, the feedback effect, caused by backward-looking expectations, can cause momentum in asset prices (Cutler et al. 1990). If expectations are backward looking, current rapid housing price growth induces positive expectations regarding future housing appreciation. These expectations may fulfill themselves in the relatively short run. Early empirical evidence of backward-looking expectations in the housing market is provided by Case and Shiller (1989) and Mankiw and Weil (1989), and more recently the existence of backward-looking expectations has been confirmed by numerous empirical articles. If backward-looking expectations are assumed, the short-term mean averting tendency of housing prices can be explained in the context of the housing market stock-flow model. According to Black et al. (2006) and Fraser et al. (2008) "momentum trading", caused by the feedback effect, has notably contributed to housing price bubbles in the U.K. and New Zealand. Similarly, a tendency for investors and households to underreact to new information, another explanation offered by the behavioralists, could explain the short-run momentum (e.g. Daniel et al. 1998). If the full impact of new important information is only grasped over a relatively long period of time, housing prices will exhibit momentum.

Importantly, the feedback effect may also strengthen the longer-run mean reversal of housing prices. Because of feedback, prices may substantially overreact upwards after a positive shock before the mean reversion starts. Then, the feedback effect may cause the price level to overreact downwards (e.g. Shiller 2003). Indeed, De Bondt et al. (1985) argue that investors are subject to waves of optimism and pessimism which may add to short-run momentum and longer-run mean reversion.

Short-term mean aversion and long-term mean reversion have been documented also in the financial asset returns (e.g. Fama, French 1988; Lo, MacKinlay 1988; Cutler et al. 1990; Campbell, Viceira 2005), although there are no similar structural reasons (the sluggish adjustment of supply and high transaction costs, for instance) as in the housing market. Even regarding the financial asset returns, it is hard to state with certainty whether these dynamics imply informational inefficiencies: the observed time series patterns might be due

\footnotetext{
${ }^{1}$ For an overview of the irrational features suggested and documented in the behavioral finance literature, see Stracca (2004).
}

to time-varying expected returns, or the potential gains from the predictability might not be enough to overcome the costs of trading (Fama 1991). The latter is particularly relevant in housing markets that exhibit large transaction costs and relatively low liquidity.

Importantly, the magnitude and length of mean aversion and subsequent reversion may well vary across regions and between dwelling types because of informational factors and due to differences in transaction costs, construction costs, and supply restrictions (Clapp et al. 1995; Capozza et al. 2004; Oikarinen 2006; Glaeser et al. 2008). Since the informational and other factors may induce contradicting forces with respect to momentum and reversion, it is essentially an empirical question to study the variation across housing markets. Previous empirical evidence documents notable regional differences in the time series patterns of housing prices (e.g. Case, Shiller 1989, 1990; Malpezzi 1999; Capozza et al. 2004).

The above mentioned studies on housing market dynamics typically use data for the U.S. and are based on econometric models that cater for relatively short-term autocorrelation dynamics only. This study, instead, investigates the persistence and reversion dynamics in housing prices by conducting variance ratio tests and accounting for autocorrelations up to 40 quarters. $\mathrm{Gu}$ (2002) and Schindler (2013) compute variance ratio statistics to study housing price momentum and reversion. $\mathrm{Gu}$ (2002), using U.S. data for the 1975-1999 period, finds that regional housing prices exhibit mean reversion even in the short horizon and that there are notable differences in the dynamics across regions. Schindler (2014), in turn, reports substantial mean aversion but no long-term reversion in the U.K. housing markets. However, these studies account for autocorrelations up to 3-4 years only.

\section{DATA DESCRIPTION}

The empirical analysis is based on quarterly hedonic price indices of privately-financed dwellings provided by Statistics Finland. The 15 Finnish cities in our sample incorporate the main growth centers, including the ten largest cities in population, as well as some smaller and more peripheral cities such as Rovaniemi in Lapland and the contracting city of Kajaani with less than 40,000 inhabitants. Since vast majority of the privatelyfinanced rental housing, i.e., of the free-market investment housing, are flats, the analysis focuses on flats. Moreover, the flat data are less complicated 
than single-family housing data due to the more homogenous and liquid underlying asset, and the only city for which Statistics Finland publishes a hedonic price index for single-family housing is the Helsinki Metropolitan Area (HMA) ${ }^{2}$. The flat and single-family housing data for HMA and for the whole of Finland are used to compare the momentum and mean reversion patterns between the two housing types.

The indices cover a period from 1987Q1 to 2010Q4. In this paper, only real indices and returns are used. Hence, the nominal indices are deflated by the cost of living index ${ }^{3}$. Furthermore, log returns are used throughout the paper.

Only the capital returns are considered in the analysis, since there are no sufficient regional level rental price or maintenance cost data at the quarterly frequency in Finland. In general, it is the price growth component that causes the volatility in housing returns and the rental income is quite stable over time. Therefore, it is reasonable to assume that the time series patterns of housing returns are driven by price movements. Indeed, data at annual frequency confirm that the autocorrelation structure (at least up to four lags) is practically identical between capital returns and total returns in all the considered markets. Hence, it is reasonable to use the capital returns to study momentum and mean reversion in housing returns.

The empirical analysis also includes stock and bond price data for the Finnish market. The OMX Helsinki CAP index (OMXHCAP) measures the stock market performance, while the Datastream all maturities government bond index is used to examine the bond return patterns ${ }^{4}$. Also these indices are in real terms and in the log form. Figure 1 shows all the indices used in the analysis for the regional housing markets, and Figure 2 graphs the country level indices.

The housing price overshot in Finland that followed the financial market liberalization in the end of the 1980s can be well seen in Figure 1. The overshot was followed by a sharp drop in the hous-

\footnotetext{
${ }^{2}$ HMA, as defined here, consists of Helsinki and the three nearest surrounding municipalities Espoo, Kauniainen and Vantaa.

${ }^{3}$ Deflation does not notably affect the results.

4 Total return index for bonds is available only since 1995. The variance ratios differ only slightly between the price and total return indices over the period from 1995 to 2010. Therefore, the price index that covers a notably longer sample period, from 1989Q1 to 2010Q4, is used in the analysis. Similar to housing returns, the volatility of bond returns generally comes from price movements while the coupon payments are stable over time.
}

ing price level that was strengthened by a severe recession of the Finnish economy. Since the mid 1990s real housing prices have increased substantially all over the country, and the price drop due to the subprime crisis was only slight and short.

Table 1 presents summary statistics for the real housing, stock, and bond price changes. Due to the greater value of land, and thereby greater "land leverage" (Bostic et al. 2007), the volatility of housing price changes is expected to be greater in larger and more densely populated cities. However, the Finnish price indices suggest the volatility to be the greatest in small cities. This is most likely due to the relatively thin housing markets in the smaller cities. For instance, in Seinäjoki the average number of quarterly transactions during the sample period is 67, while it is over 3,400 in HMA. Because of the small number of observations per period in the smaller markets, the hedonic housing price indices are not able to track the actual price development as well in these regions as in the larger cities. In other words, the price indices of the small markets include more "noise", i.e., more variation that is due to the heterogeneity of housing rather than due to actual price changes. Similarly, the autocorrelation coefficients are likely to be substantially downwards biased in the case of the smaller markets. Therefore, the standard deviations and autocorrelations that are reported in Table 1 are based on Hodrick-Prescott (H-P) filtered housing price indices that should extract, to a notable extent, the "noise" in the series. These values are likely to give a better indication of the relative magnitudes of the volatilities and autocorrelations across the cities.

It is reasonable to believe that the H-P filtered series give good approximations of the actual volatilities and autocorrelations. While the smoothing parameter, lambda, is small enough (0.5) not to extract the actual short-run dynamics, at least to a significant magnitude, the filtered return volatilities of the smaller cities are notably lower than those based on the original series and than those of the larger cities (as proposed by theory). ${ }^{5}$ This supports the claim that the high volatility of the smaller markets in the original data is, at least to a notable extent, due to additional noise in the price series. For comparison, the statistics that are based on the non-filtered data are reported in parentheses in Table 1.

\footnotetext{
${ }^{5}$ Case and Shiller (1989) suggest that when price indices are measured with some error, persistence of the perceived variables is smaller than that of the actual variables.
} 

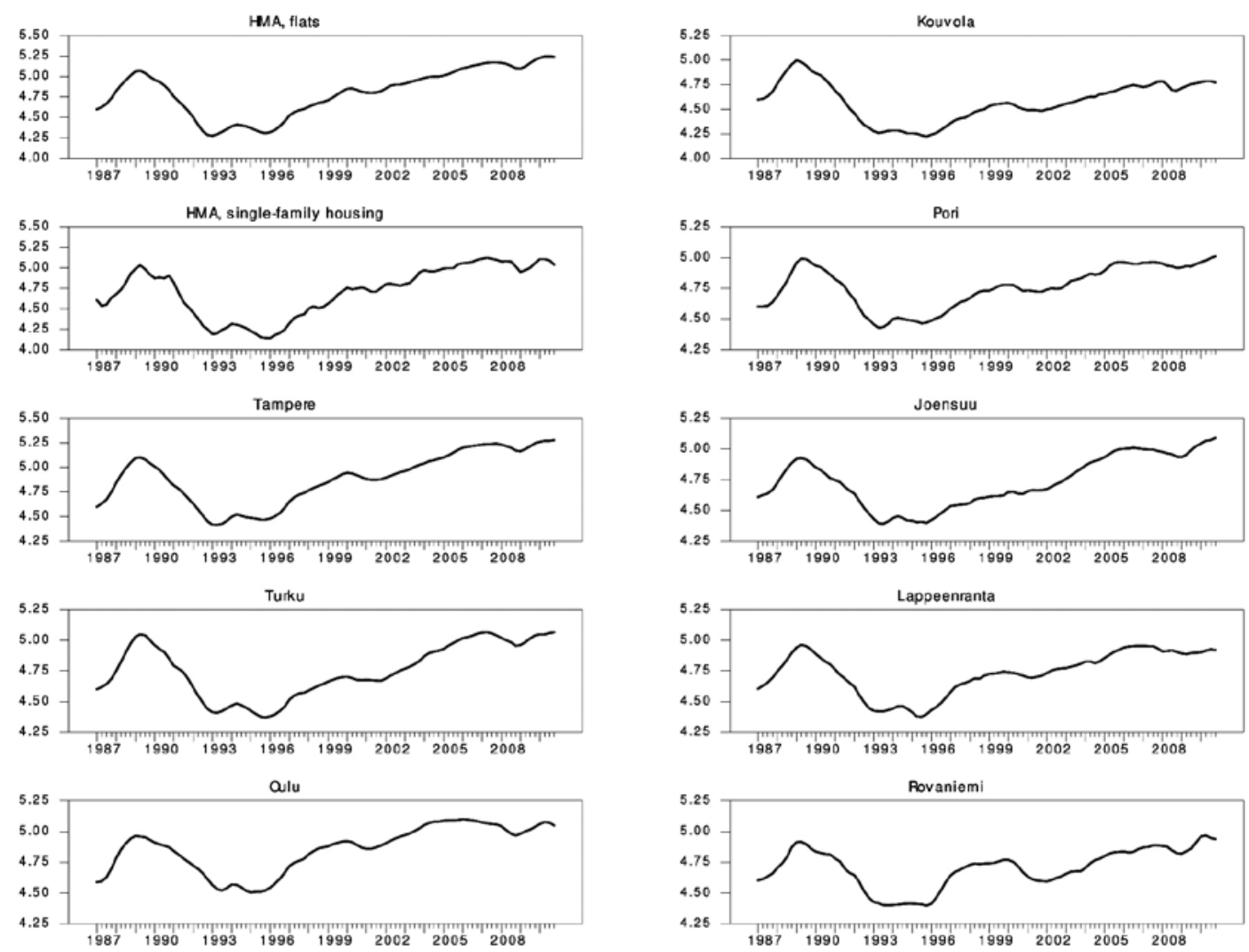

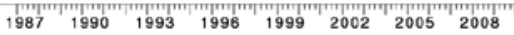
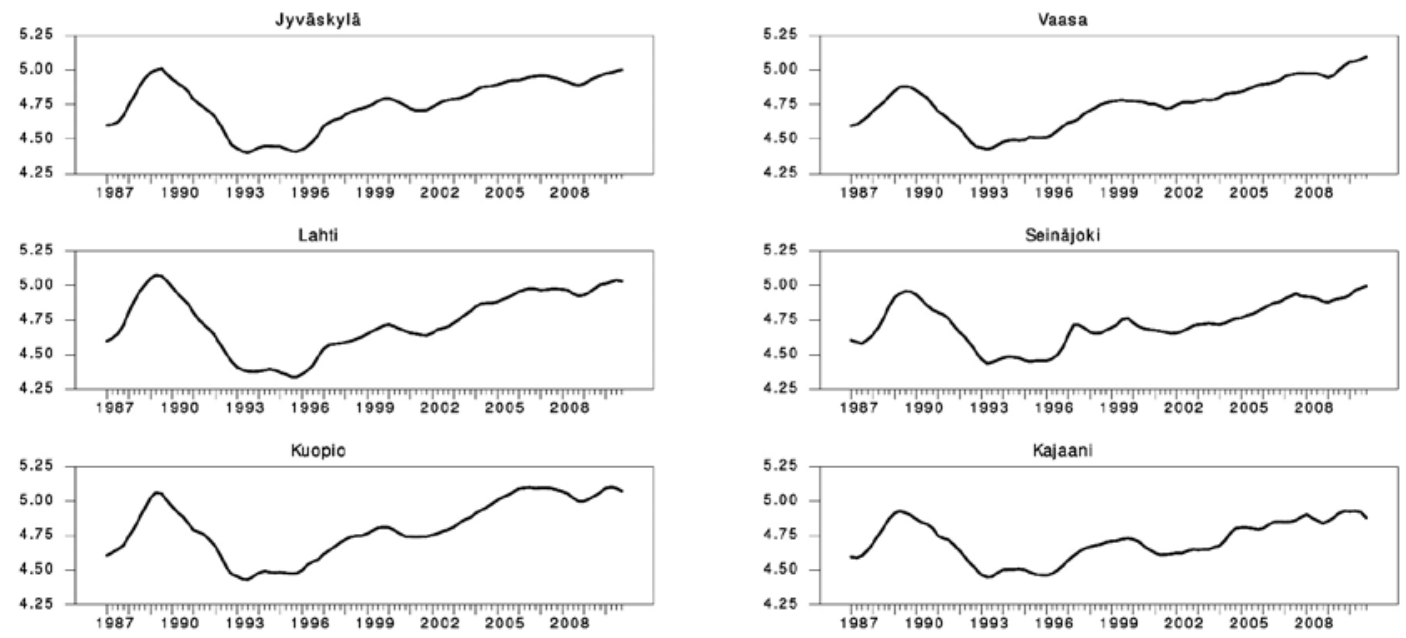

Fig. 1. Housing price indices for Finnish regional markets
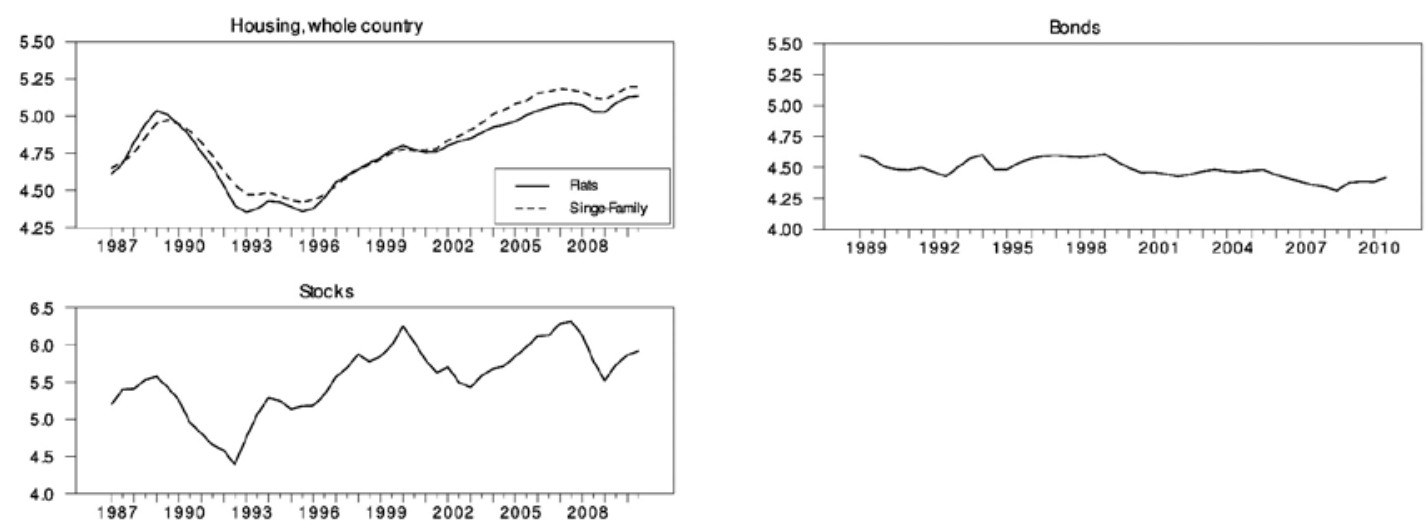

Fig. 2. Housing, stock, and bond indices for the whole of Finland 
Table 1. Descriptive statistics for the real price changes over the period from 1987 to 2010

\begin{tabular}{|c|c|c|c|c|c|c|}
\hline Market & $\begin{array}{l}\text { Trans. vol. } \\
\text { (turnov. \%) }\end{array}$ & $\begin{array}{l}\text { Mean } \\
\%\end{array}$ & $\begin{array}{l}\text { S.D. } \\
\%\end{array}$ & $\begin{array}{l}\text { Jarque- } \\
\text { Bera }\end{array}$ & $\begin{array}{l}\text { 1st order } \\
\text { autocorr }\end{array}$ & $\begin{array}{l}\text { 2nd order } \\
\text { autocorr }\end{array}$ \\
\hline \multicolumn{7}{|l|}{ FINLAND } \\
\hline HMA & $3,433(3.6 \%)$ & 2.7 & $7.2(8.1)$ & $.07(.04)$ & $.91(.70)$ & $.71(.51)$ \\
\hline Tampere & $811(4.0 \%)$ & 2.9 & $6.5(7.5)$ & $.84(.15)$ & $.92(.61)$ & $.74(.52)$ \\
\hline Turku & $761(3.8 \%)$ & 2.0 & $6.1(7.5)$ & $.54(.07)$ & $.90(.47)$ & $.72(.44)$ \\
\hline Oulu & $341(3.3 \%)$ & 2.0 & $5.1(6.5)$ & $.11(.22)$ & $.88(.39)$ & .67 (.39) \\
\hline Jyväskylä & $282(3.6 \%)$ & 1.6 & $5.6(7.4)$ & $.26(.07)$ & $.89(.30)$ & $.71(.42)$ \\
\hline Lahti & $392(4.1 \%)$ & 1.9 & $6.2(7.4)$ & $.79(.15)$ & $.92(.57)$ & $.75(.48)$ \\
\hline Kuopio & $289(4.1 \%)$ & 2.0 & $5.9(8.0)$ & $.11(.00)$ & $.88(.27)$ & $.69(.33)$ \\
\hline Kouvola & $123(3.4 \%)$ & 0.7 & $6.1(9.1)$ & $.38(.04)$ & $.86(.11)$ & $.66(.27)$ \\
\hline Pori & $181(4.2 \%)$ & 1.5 & $5.4(8.6)$ & $.27(.49)$ & $.84(.02)$ & $.63(.21)$ \\
\hline Joensuu & $148(3.1 \%)$ & 1.9 & $4.9(7.4)$ & $.53(.42)$ & $.85(.08)$ & $.65(.24)$ \\
\hline Lappeenranta & $157(3.5 \%)$ & 1.3 & $5.1(7.6)$ & $.48(.11)$ & $.87(.07)$ & $.68(.34)$ \\
\hline Rovaniemi & $111(3.5 \%)$ & 1.4 & $5.5(8.5)$ & $.42(.02)$ & $.84(.05)$ & $.62(.24)$ \\
\hline Vaasa & $175(3.1 \%)$ & 1.9 & $4.2(6.9)$ & $.02(.32)$ & $.84(-.01)$ & $.65(.19)$ \\
\hline Seinäjoki & $67(3.7 \%)$ & 1.4 & $5.8(9.3)$ & $.03(.00)$ & $.81(-.04)$ & $.53(.29)$ \\
\hline Kajaani & $85(3.9 \%)$ & 1.5 & $5.0(8.1)$ & $.91(.14)$ & $.83(-.02)$ & $.59(.29)$ \\
\hline Finland & $10,441(3.4 \%)$ & 2.2 & $6.1(6.7)$ & $.11(.16)$ & $.92(.71)$ & $.74(.57)$ \\
\hline HMA, single-family & $98(0.4 \%)$ & 1.7 & $9.1(19.6)$ & $.22(.68)$ & $.68(-.34)$ & $.37(.22)$ \\
\hline Finland, single-family & $1,953(0.1 \%)$ & 2.3 & $4.8(6.2)$ & $.07(.35)$ & $.90(.34)$ & $.74(.35)$ \\
\hline Stocks & & 2.8 & 22.9 & .31 & .39 & .09 \\
\hline Bonds (1989-2010) & & -1.0 & 5.0 & .22 & .29 & .01 \\
\hline
\end{tabular}

Note: The cities are ordered by population in 2010. Mean is the annualized average log change of the price level, S.D is the annualized standard deviation of the log price change, and Jarque-Bera shows the p-value for the null of normally distributed price changes in the Jarque-Bera test. The value in the parenthesis is based on non-filtered index, whereas the value outside the parenthesis is computed from the H-P filtered price index. The table also presents the transaction volume in each regional market during 1987-2010 and the turnover rate (annual transaction volume / total stock, 2010) in parentheses. There have been several changes in the administrational geographical boundaries of the cities during 2008-2010. The figures correspond to the city boundaries prior to the changes.

Expectedly, the volatility based on the filtered series is notably greater in HMA than in the other areas - after all, HMA is by far the largest and most expensive regional market in Finland and in HMA land leverage is the highest in the country. The filtering also substantially changes the autocorrelation figures in the smaller markets. That is, due to the measurement error in the indices, the original series hide the strong positive autocorrelation in housing price movements in the small cities. The filtered price changes generally appear to be approximately normally distributed. The large estimated first- and second-order autocorrelations, the first-order autocorrelation coefficients being between 0.81 and 0.92 and the second-order autocorrelation coefficients between 0.53 and 0.74 across the cities, suggest that there is a strong momentum effect in housing prices regardless of the region. As the stock and bond markets do not have the same asset heterogeneity and market thinness complications as the housing market, the stock and bond indices are not filtered.

\section{METHODOLOGY}

\subsection{Variance ratio analysis}

This study uses the variance ratio (VR) approach, suggested by Lo and MacKinlay (1988, 1989), to examine the time series patterns of asset returns. The VR statistics investigate the proportionality of variance of q-period horizon returns with the variance of one-period returns. For a random walk series, the variance of q-period returns is q times the variance of one-period returns. For example, if an asset price series follows a random walk, the variance of its one-year returns will be four times as large as the variance of its quarterly returns.

The null hypothesis in the variance ratio test is that of a random walk. Under the random walk hypothesis, a non-predictable random mechanism generates the behavior of returns. In the simplest version of a random walk model, the index value in period $t$ equals the previous index value plus the realization of a random variable $\varepsilon_{t}$,

$$
I_{t}=I_{t-1}+\varepsilon_{t}
$$


where: $I_{t}$ is the natural $\log$ of the index and $\varepsilon_{t}$ is a random disturbance term at time $t$ which satisfies $\mathrm{E}\left[\varepsilon_{\mathrm{t}}\right]=0$ and $\mathrm{E}\left[\varepsilon_{\mathrm{t}} \varepsilon_{\mathrm{t}-\mathrm{h}}\right]=0, \mathrm{~h} \neq 0$ for all $\mathrm{t}$. If the expected index changes are given by $\mathrm{E}\left[\Delta \mathrm{I}_{\mathrm{t}}\right]=\mathrm{E}\left[\varepsilon_{\mathrm{t}}\right]=0$, the best linear estimator for index $\mathrm{I}_{\mathrm{t}}$ is the previous index value $I_{t-1}$. Under the assumption that expected index changes $\mu$ are constant over time, the random walk model expands to a random walk with drift $(\mu=$ drift parameter):

$$
\begin{aligned}
\mathrm{I}_{\mathrm{t}} & =\mathrm{I}_{\mathrm{t}-1}+\mu+\varepsilon_{\mathrm{t}} \text { or } \Delta \mathrm{I}_{\mathrm{t}}=\mu+\varepsilon_{\mathrm{t}}, \\
\varepsilon_{\mathrm{t}} & \sim \text { i.i.d. }\left(0, \sigma^{2}\right) .
\end{aligned}
$$

The random walk implies uncorrelated price changes, $\Delta \mathrm{I}_{\mathrm{t}} ; \varepsilon_{\mathrm{t}} \sim$ i.i.d. $\left(0, \sigma^{2}\right)$ denotes that the increments $\varepsilon_{\mathrm{t}}$ are independently and identically distributed (i.i.d.) with $\mathrm{E}\left[\varepsilon_{\mathrm{t}}\right]=0$ and $\mathrm{E}\left[\varepsilon_{\mathrm{t}}{ }^{2}\right]=\sigma_{\varepsilon}{ }^{2}$.

The traditional random walk tests on the basis of serial correlation and unit roots are vulnerable to errors due to autocorrelation induced by nonsynchronous and infrequent trading. A discussion on this topic with respect to house price indices with a small sample size can be found in Case and Shiller (1989). To resolve this shortcoming, Lo and MacKinlay $(1988,1989)$ developed tests for random walks based on variance ratio estimators.

The variance of the increments of a random walk is linearly time-dependent. Thus, if the natural logarithm of index, $\mathrm{I}_{\mathrm{t}}$, follows a pure random walk with drift [Equation (2)], the variance of index changes should increase proportionally to the observation interval q. Suppose a series of nq +1 price observations $\left(\mathrm{P}_{0}, \mathrm{P}_{1}, \mathrm{P}_{2}, \ldots, \mathrm{P}_{\mathrm{nq}}\right)$ measured at uniform intervals is available. If this time series follows a random walk, the variance of the qth difference would correspond to $q$ times the variance of first differences. Following Equations (1) and (2), the variance of the first differences, denoted as $\hat{\sigma}^{2}\left[I_{t}-I_{t-1}\right]$ and $\hat{\sigma}^{2}\left[r_{t}\right]$, respectively, grows linearly over time so that the variance of the qth difference is

$$
\begin{aligned}
& \hat{\sigma}^{2}\left[I_{t}-I_{t-q}\right]=q \cdot \hat{\sigma}^{2}\left[I_{t}-I_{t-1}\right] \\
& \text { or } \\
& \hat{\sigma}^{2}\left[r_{t}(q)\right]=q \cdot \hat{\sigma}^{2}\left[r_{t}\right] .
\end{aligned}
$$

For the qth lag in $\mathrm{I}_{\mathrm{t}}$, where $\mathrm{q}$ is any integer greater than one, the variance ratio, VR(q), is defined as:

$$
V R(q) \equiv \frac{\hat{\boldsymbol{\sigma}}^{2}\left[r_{t}(q)\right]}{q \cdot \hat{\boldsymbol{\sigma}}^{2}\left[r_{t}\right]}=1+2 \sum_{h=1}^{q-1}\left(1-\frac{h}{q}\right) \cdot \hat{\rho}(h),
$$

where: $\hat{\sigma}^{2}[\cdot]$ is an unbiased estimator of the variance. The expected value of VR(q) is one under the null hypothesis of a random walk for all values of q. While $I_{t}$ describes the logarithmic price process, $r_{t}(q)$ is a $q$ period continuously compounded price change with $r_{t}(q) \equiv r_{t}+r_{t-1}+\ldots+r_{t-q+1}=I_{t}-I_{t-q}$. $\hat{\rho}(h)$ is the estimator of the hth serial correlation coefficient. Alternatively, values for VR(q) greater than one imply mean aversion while values smaller than one imply mean reversion. Equation (4) shows that VR(q) is a particular linear combination of the first $\mathrm{h}-1$ autocorrelation coefficients with linearly declining weights. If $q$ behaves like a random walk, $\operatorname{VR}(q)=1$ because $\hat{\rho}(h)=0$ for all $h \geq 1$ (Campbell et al. 1997).

Under the null hypothesis of a homoscedastic increments random walk, Lo and MacKinlay (1988) derive an asymptotic standard normal test statistic for the VR. The standard z-test statistic is:

$$
Z_{1}(q)=\frac{V R(q)-1}{\sqrt{\hat{\theta}_{1}(q)}}=\frac{M_{r}(q)}{\sqrt{\hat{\theta}_{1}(q)}} \sim N(0,1),
$$

where: $\hat{\theta}_{1}(q)=\frac{2(2 q-1)(q-1)}{3 q(n q)}$, and $\stackrel{a}{\sim}$ denotes that the distributional equivalence is asymptotic.

Many time series have time-varying volatilities, with returns deviating from normality. When index changes are conditionally heteroscedastic over time, there may not exist a linear relation over the observation intervals. Hence, Lo and MacKinlay (1988) suggest a second test statistic $\mathrm{Z}_{2}(\mathrm{q})$ with a heteroscedasticity-consistent variance estimator $\hat{\theta}_{2}(q)$ :

$$
\begin{aligned}
& Z_{2}(q)=\frac{V R(q)-1}{\sqrt{\hat{\theta}_{2}(q)}}=\frac{M_{r}(q)}{\sqrt{\hat{\theta}_{2}(q)}} \stackrel{a}{\sim} N(0,1), \\
& \text { with } \hat{\theta}_{2}(q)=\sum_{j=1}^{q-1}\left[\frac{2(q-j)}{q}\right]^{2} \cdot \hat{\delta}(j) \text { and } \\
& \hat{\delta}(j)=\frac{\sum_{t=j+1}^{n q}\left(I_{t}-I_{t-1}-\hat{\mu}\right)^{2}\left(I_{t-j}-I_{t-j-1}-\hat{\mu}\right)^{2}}{\left[\sum_{t=1}^{n q}\left(I_{t}-I_{t-1}-\hat{\mu}\right)^{2}\right]} .
\end{aligned}
$$

If the null hypothesis is true, the modified heteroscedasticity-consistent test statistic in Equation (6) has an asymptotic standard normal distribution (Liu, He 1991). The $\mathrm{Z}_{2}$ (q)-statistic is robust to heteroscedasticity as well as to non-normal disturbance terms.

To get more observations concerning the longhorizon returns, we use overlapping returns to compute the VR statistics. The use of overlapping returns yields a more efficient estimator and a more powerful test (Campbell et al. 1997). Since even the number of overlapping observations is relatively small, the conventional variance ratio test can show small sample deficiencies. Therefore, we report VR test results that are computed by 
the Wild bootstrap method (Kim 2006) with 1,000 replications and a normal error distribution ${ }^{6}$. The Wild bootstrap method is based on the heteroscedasticity-consistent test statistic. Variance ratios up to 40 quarters are investigated in this study ${ }^{7}$.

\subsection{Runs test}

The often applied autocorrelation and VR tests alike are based on the assumption of a linear process and both approaches thus test for linear dependencies by definition when challenging the random walk hypothesis. The non-parametric runs test, instead, investigates the independence of successive price changes and does not require normality or a linear process.

A runs test determines whether the total number of runs in the sample is consistent with the hypothesis that price changes are independent. If the series of price changes exhibits a greater tendency of change in one direction, the average run will be longer and, consequently, the number of runs will be lower than when generated by a random process. In the Bernoulli case for a binary random variable, the total number of runs is referred to as $\mathrm{N}_{\text {Runs }}$ and the total expected number of runs is given by:

$$
\mathrm{E}\left[\mathrm{N}_{\text {Runs }}\right]=2 \mathrm{np}(1-\mathrm{p})+\pi^{2}+(1-\mathrm{p})^{2},
$$

where: $\pi=\operatorname{Pr}\left(r_{t}>0\right)=\Phi\left(\frac{\mu}{\sigma}\right), \mu$ is the expected index change, and $\sigma$ its standard deviation.

For large sample sizes $(\mathrm{N}>30)$, the sampling distribution of $\mathrm{E}\left[\mathrm{N}_{\mathrm{Runs}}\right]$ is approximately normal and a continuity correction is produced. Based on the expected index change and the standard deviation, we calculate the standardized Z-value from the standardized normal distribution.

When the actual number exceeds (falls below) the expected runs, a positive (negative) Z-value is obtained. Consequently, a positive (negative) $\mathrm{Z}$-value indicates negative (positive) serial correlation in the series of index changes.

\section{EMPIRICAL FINDINGS}

\subsection{Finnish regional housing markets}

Figure 3 pictures the VR values for flats in each of the regional housing markets. The vertical axis

\footnotetext{
${ }^{6}$ Kim's (2006) simulations indicate that the test results are generally insensitive to the choice of the Wild bootstrap distribution.

${ }^{7}$ Longer-horizon returns are not tested. This is because the number of observations gets overly small as the horizon is lengthened and because there are also other difficulties with inferences when the horizon is large relative to the total time span (see Campbell et al. 1997).
}

shows the VR values and the horizontal axis shows the investment horizon. Clearly, none of the housing price series follows the random walk. In all the markets the VR values are statistically significantly greater than one at almost all the horizons. Momentum lasts for a long time period regardless of the market. Even in Pori, where mean reversion starts the earliest, VR peaks at the 15-quarter horizon. In Turku and Joensuu, in turn, VR peaks the latest, i.e., after 22 quarters. That is, the momentum effect appears to last for approximately 4 to 5 years. The filtering of the price series does not influence the timing of the peak in the VR curves.

The VR curves reveal notable differences in both the momentum and reversion dynamics across regions. For instance, while the maximum VR is 7.5 in Joensuu, it is only slightly over half of that in Seinäjoki. In most of the cities the VR curves drop substantially in the long run after peaking at the 4 to 5 year horizon.

In each city, the filtered price indices naturally yield greater VRs than the original series. Generally, the smaller the market, the bigger this "correction" is. The applied H-P filtering appears to work well in the sense that the maximum VRs do not significantly correlate with the transaction volumes of the markets. In contrast, there is strong positive correlation (.67) between transaction volume and the VRs that are based on the non-filtered price series, indicating that the index noise in the small markets diminishes the observed autocorrelations - exactly the reason for using the filtered series in the analysis.

The high variance ratios indicate notable predictability and horizon effect in housing price movements: higher (lower) than average returns today predict higher (lower) than average returns in the future. As the VRs stay substantially over one even in the long horizon, housing is a notably riskier asset in the long term than suggested by the quarterly or annual variance figures. Even the smallest observed VR is two at the 40 quarter horizon. The observed substantial momentum effect is in line with the VR statistics reported by Schindler (2014) regarding the U.K. housing market, with the findings of Glaeser and Gyourko (2007) according to which momentum lasts for over 3 years in the U.S. housing market, and with Capozza et al. (2004) whose estimations show that housing price overshot peaks at around 4 years after a shock in the fundamentals in the U.S.

As a robustness check, we conduct runs test to examine the non-parametric persistence in the regional price series. Table 2 reports the runs test 

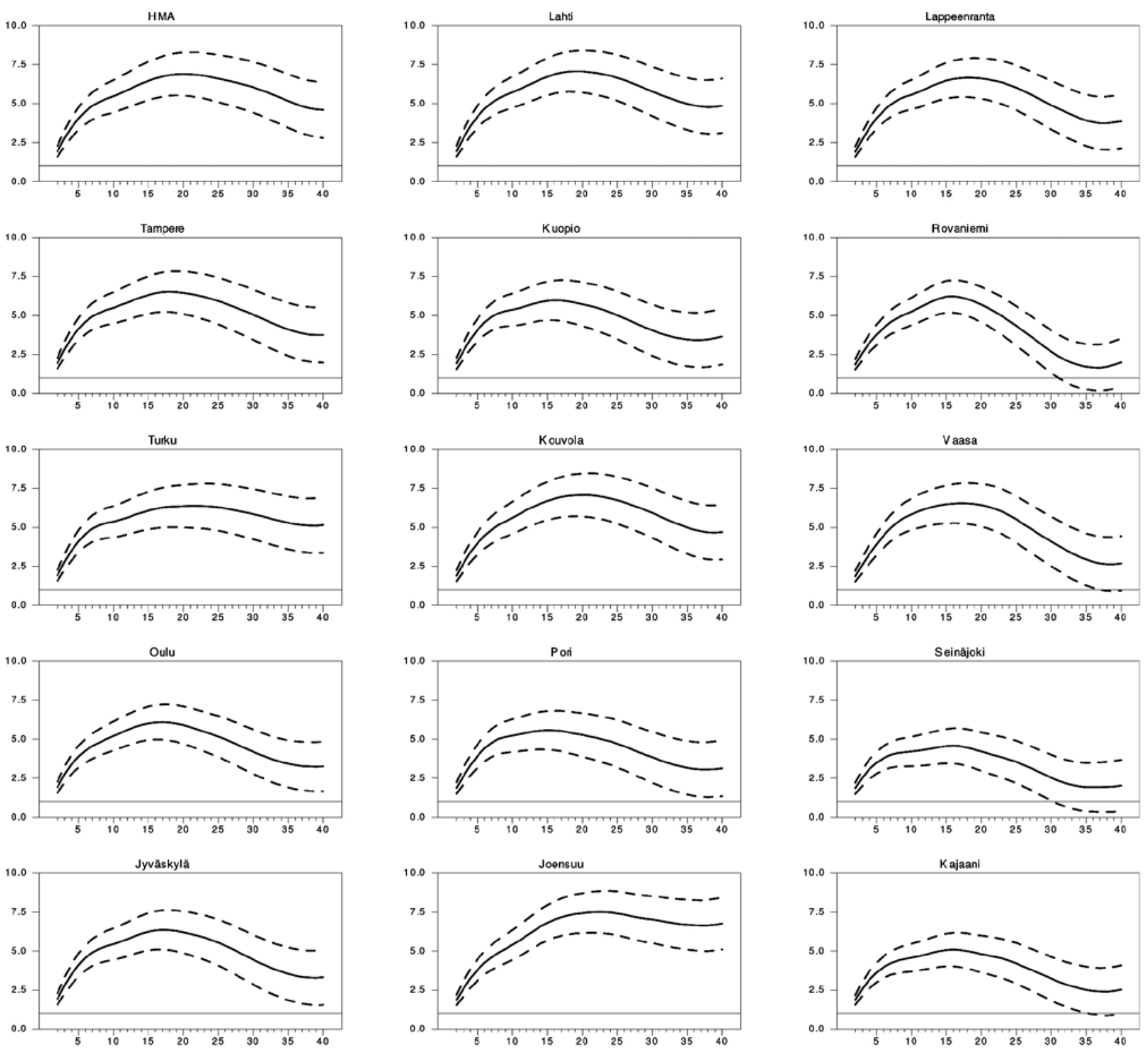

Notes: The figure shows the VRs at each horizon until 40 quarters with \pm 2 standard error bands. The horizontal axis shows the investment horizon. A vertical grid line crosses at value 1 in each of the graphs.

Fig. 3. VR curves for flats in the Finnish regional markets

results. The test statistics are high, have a negative sign and are highly significant. This means that the number of empirically observed runs is lower that the number of expected runs under the random walk hypothesis, which is equivalent to strong persistence. Thus, in line with the findings from the VR tests, we find strong persistence in all the distinct Finnish housing markets.

Previous empirical evidence (Oikarinen 2009a, 2009b) suggests that the financial market liberalization induced a structural change in the housing price dynamics in Finland in the late 1980s. In particular, the findings suggest that the interac- tion between housing prices and the availability of mortgage finance has notably increased after the liberalization. Since the interaction between housing prices and the credit availability may induce self-reinforcing cycles between housing and credit markets, the momentum effect may have become greater and the longer-run mean reversion stronger after the deregulation. To investigate whether this is the case, we conduct VR tests separately for the 1970Q1-1986Q4 period and the 1987Q12010Q4 period for HMA, Tampere, Turku and Oulu. For the rest of the cities as long housing price data are not available. The VR ratio statistics 
Table 2. Results from the runs test

\begin{tabular}{|c|c|c|c|}
\hline \multirow[t]{2}{*}{ Market } & \multicolumn{2}{|l|}{ Runs } & \multirow{2}{*}{ Test statistics } \\
\hline & $\begin{array}{l}\text { actual } \\
\text { NRuns }\end{array}$ & $\begin{array}{l}\text { expected } \\
\text { E[Runs] }\end{array}$ & \\
\hline Finland & 10 & 47 & $-7.23^{* * *}$ \\
\hline HMA & 10 & 47 & $-7.20 * * *$ \\
\hline Tampere & 9 & 47 & $-7.27 * * *$ \\
\hline Turku & 11 & 47 & $-7.10^{* * *}$ \\
\hline Oulu & 14 & 47 & $-6.40 * * *$ \\
\hline Jyväskylä & 11 & 47 & $-7.13^{* * *}$ \\
\hline Lahti & 12 & 47 & $-6.95^{* * *}$ \\
\hline Kuopio & 16 & 47 & $-6.08^{* * *}$ \\
\hline Kouvola & 14 & 48 & $-6.73^{* * *}$ \\
\hline Pori & 22 & 47 & $-4.88^{* * *}$ \\
\hline Joensuu & 17 & 47 & $-5.72^{* * *}$ \\
\hline Lappeenranta & 16 & 47 & $-6.18^{* * *}$ \\
\hline Rovaniemi & 16 & 48 & $-6.19 * * *$ \\
\hline Vaasa & 15 & 46 & $-5.96^{* * *}$ \\
\hline Seinäjoki & 16 & 47 & $-6.15^{* * *}$ \\
\hline Kajaani & 25 & 48 & $-4.38^{* * *}$ \\
\hline Stocks & 31 & 48 & $-3.23 * * *$ \\
\hline Bonds & 38 & 43 & -0.96 \\
\hline
\end{tabular}

Notes: The null hypothesis is that of random walk. ${ }^{* * *}, * *$ and $*$ indicate statistical significance at the $1 \%, 5 \%$, and $10 \%$ level; critical values for the runs test at the $1 \%, 5 \%$ and $10 \%$ significance level are derived from standard normal distribution. The cities are ordered in the Table by population in 2010: the biggest city is HMA and the smallest one is Kajaani.

do not support the hypothesis of increased momentum and reversion since 1987. On the contrary, it seems that prior to the financial liberalization momentum was even stronger and the eventual mean reversion even greater than during the period from 1987 to 2009. This may imply increase in housing market efficiency since the late 1980s.

In contrast with the hypothesis that the markets with greater number of transactions should be more informationally efficient than the smaller markets and with the empirical results of Capozza et al. (2004) regarding the U.S. housing markets, market size is not positively correlated with more rapid mean reversion of housing prices in Finland. Instead, the correlation coefficient between the length and magnitude of momentum and the market size (transaction volume, population) is positive, though not statistically significant. Moreover, the correlation between the magnitude of longterm mean reversion and market size is negative. Simple correlation analysis also implies that longterm mean reversion is weaker in the markets where the momentum lasts longer.

A potential explanation to the apparently positive relationship between momentum and market size is the fact that in areas where land is a more scarce resource housing supply can typically adjust more slowly to shocks, due to which housing prices may be more serially correlated. In general, land is a scarcer resource in the larger and more densely built areas, such as HMA, than in the smaller more sparsely built cities.

\subsection{Dwelling types: flats vs. single-family housing}

Mean reversion starts earlier in the flat market than in the single-family housing market; the difference is approximately one year both in HMA and the whole of Finland (see Figure 4). The better liquidity in the flat market is likely to have a role in the difference between the dwelling types, as better liquidity generally yields greater information flows and informational efficiency. Also the notably higher transaction costs in the single-family housing market probably contribute to the longer duration of momentum in that market ${ }^{8}$.

\footnotetext{
${ }^{8}$ In Finland, the transaction tax is as large as $4 \%$ for single-family housing, whereas it was $1.6 \%$ for flats at the end of the sample period.
} 

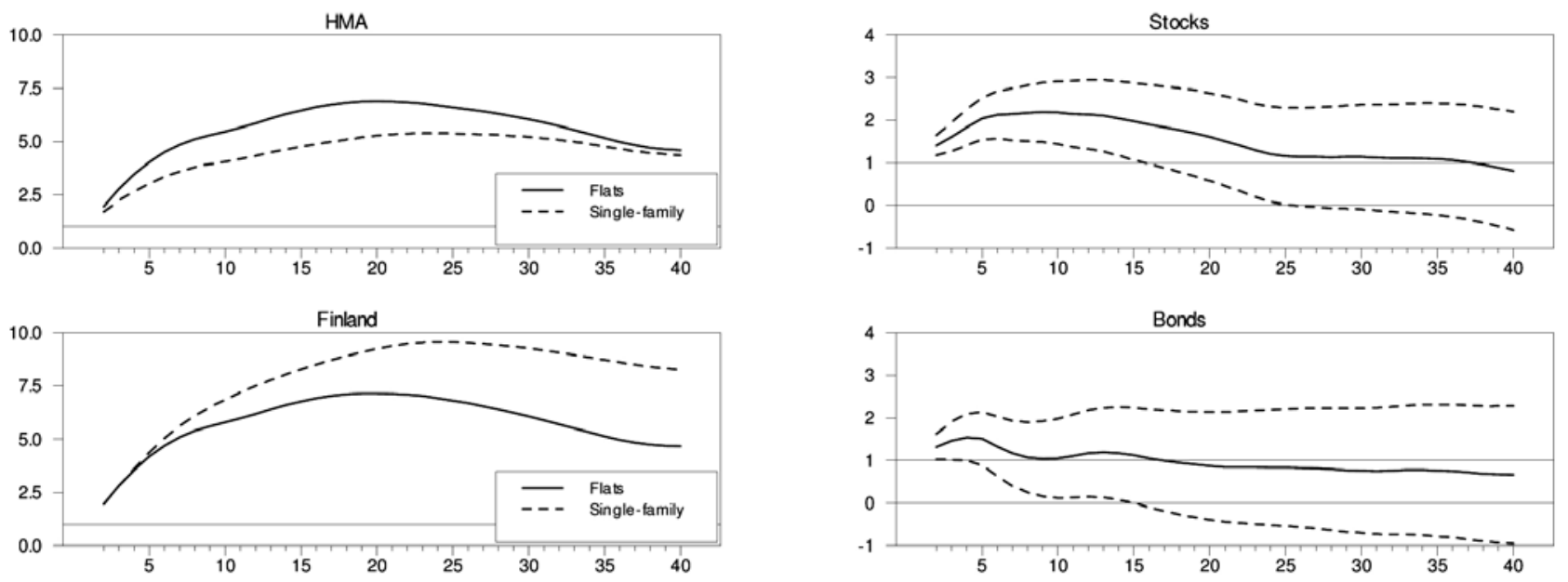

Note: The figure shows the VRs at each horizon until 40 quarters with \pm 2 standard error bands. A vertical grid line crosses at value 1 in each of the graphs.

Fig. 4. VR curves for flats, single-family housing, stocks and bonds in the whole of Finland

The results differ between HMA and the whole country regarding the magnitude of momentum, though. While flats exhibit greater momentum than single-family housing in HMA, the opposite holds for the whole country. This is likely to be due to the fact that a much greater part of the single-family housing stock than flats is located in peripheral areas of Finland. The difference between the estimated magnitudes of momentum is not statistically significant between the HMA flat and single-family housing markets, but it is significant between the markets in the whole country.

\subsection{Asset markets: housing vs. stocks and bonds}

Figure 4 also shows the VR curves for Finnish stock and bond returns. The stock market exhibits only slight momentum compared with the housing market. Moreover, stock prices start to mean revert much more rapidly than housing prices, and in the long horizon stock market volatility does not appear to be any greater than in the short run: the long-horizon VRs are not significantly different from one. In the bond market, mean reversion starts even faster and, with the exception of the first three quarters, there is no significant horizon effect. These results are confirmed by the runs test which indicates significant persistence in the stock market in the short run but no persistence in the bond market (Table 2).

The stronger momentum and weaker long-term mean reversion in housing prices than in stock and bond prices may explain, at least partially, the fact that typically the share of housing (and real estate in general) in institutional portfolios is considerably smaller than it should be based on unconditional portfolio analysis. Nevertheless, the volatility in housing price growth does not reach that of stocks even in the long horizon. While the estimated annualized standard deviation at the one-quarter investment horizon is $6.2 \%$ for country level flat price movements and $22.9 \%$ for stocks, the corresponding figures at the 10-year horizon are $13.4 \%$ and $20.6 \%$ for flats and stocks, respectively. This finding for the Finnish market is in contrast with the results of MacKinnon and $\mathrm{Al} \mathrm{Za-}$ man (2009) for the U.S., based on which real estate is as risky as equity for long-term investors.

Mean aversion up to several years in housing prices could be seen somewhat surprising, since housing supply typically reacts with a lag of approximately one year after a price shock. However, DiPasquale and Wheaton (1994) argue that, given the heterogenous product and time-consuming search in the housing market, rapid price adjustments may not be rational. It is questionable whether serial correlation up to a 4 to 5 year horizon can be explained by the market frictions, though. A potential explanation for the strong and long-lasting mean aversion is offered by the feedback theory. If the "feedback" is not interrupted, it may even produce a price bubble. The unearned increment in housing prices is made easier to occur because for most actors in the market it is almost impossible to assess the proper fundamental value for a given dwelling. Even for professional investors the judgment of fundamental value is often hard. 


\section{CONCLUSIONS}

Extensive empirical literature shows evidence of substantial short-term momentum and longerhorizon mean reversion in housing prices. These time series patterns are of great importance for an investor holding direct housing assets in her portfolio, as the investment horizon for real estate is typically long, and the patterns induce significant horizon effects that influence the relative riskiness of assets thereby affecting the optimal portfolio allocation.

The empirical studies regarding mean reversion and aversion of housing returns generally investigate horizons up to a couple of years at maximum and cater for relatively short-term autocorrelation dynamics only. Due to the potentially substantial and long-lasting momentum and reversion patterns in housing prices, the typically long holding period for direct real estate, and to the notable portfolio implications that asset return autocorrelations have, it may be important to consider considerably longer investment horizons and higherorder autocorrelations.

This paper appears to be the first one on the theme that caters for the high-order autocorrelation patterns (up to 40 quarters) of housing price movements. The empirical analysis is based on variance ratio statistics using both regional and country-level data for Finland for the period 19872010. The variance ratios, computed using Kim's (2006) Wild bootstrapping, essentially summarize the autocorrelation patterns and thereby account for the potential serial correlation in housing price movements up to a ten year horizon, and enable a detailed examination of the shapes and durations of momentum and mean reversion in housing returns. To our best knowledge, variance ratio tests that cater for such long horizon have not been applied to housing market data previously.

In line with most previous empirical evidence for other markets, our results show that housing prices do not follow the random walk model in any of the considered markets. In the Finnish market, momentum effect in housing price growth is long-lasting and considerable in size. Depending on the city, the variance ratios peak at the horizon of 4 to 5 years after which mean reversion starts. Since the eventual reversion is substantially weaker than the shorter-term mean aversion, housing is a notably riskier asset in the long term than suggested by the typically reported quarterly or annual variance figures. The findings also indicate that there can be substantial differences across regional housing markets as well as between flats and single-family housing: We observe considerable variation across cities and housing types in the duration and size of momentum as well as in the magnitude of long-term mean reversion. The observed time series properties are consistent with sentiment theories of initial under-reaction and delayed over-reaction of investors and households.

The observed length and size of momentum is substantially greater that those reported recently in studies using Vector Autoregressive (VAR) model based computations. The VAR models assume that a relatively short lag length can capture the autocorrelation dynamics. Our findings suggest that higher-order autocorrelations may well be relevant regarding the extent of actual horizon effects.

The findings have several practical implications. Since the stock and bond returns do not exhibit similar strong momentum as housing prices, the relative attractiveness of housing investments is weaker for a long-horizon investor than suggested by the unconditional portfolio analyses that employ relatively short-term variances and assume i.i.d. returns. This justifies, at least partly, the relatively small share of direct real estate investments in institutional portfolios, and has implications for credit institutions and policy makers too.

Furthermore, differences in housing price dynamics across regions influence the optimal housing portfolio allocation and highlight one more reason why it is problematic to use country-level housing price data when analyzing housing price dynamics or the optimal portfolio allocation. The high variance ratios for housing price movements also indicate significant predictability in housing returns even in the long run. The predictability makes the traditional unconditional mean-variance analysis inefficient both for short- and longhorizon investors.

In the future, it would be useful to investigate whether similar regional variation in the momentum and reversion patterns exists in other countries and to analyze in detail the reasons behind the regional variation using larger dataset than the one in this study. Given that Finland is a quite coherent country with respect to demographics and culture, the regional differences may well be even greater in many other countries. Furthermore, it would be worthwhile to conduct rigorous comparisons between VAR model based results, including the chosen lag length, and variance ratio test indications. 


\section{ACKNOWLEDGEMENTS}

The first author is grateful for financial support received from the OP-Pohjola Group Research Foundation.

\section{REFERENCES}

Barberis, N. 2000. Investing for the long run when returns are predictable, The Journal of Finance 55(1): 225-264. http://dx.doi.org/10.1111/0022-1082.00205

Beracha, E.; Skiba, H. 2011. Momentum in residential real estate, Journal of Real Estate Finance and Economics 43(3): 299-320. http://dx.doi.org/10.1007/ s11146-009-9210-2

Black, A.; Fraser, P.; Hoesli, M. 2006. House prices, fundamentals and bubbles, Journal of Business Finance \& Accounting 33(9-10): 1535-1355. http:// dx.doi.org/10.1111/j.1468-5957.2006.00638.x

Bostic, R. W.; Longhofer, S. D.; Redfearn, C. L. 2007. Land leverage: decomposing home price dynamics, Real Estate Economics 35(2): 183-208. http://dx.doi. org/10.1111/j.1540-6229.2007.00187.x

Campbell, J. Y.; Lo, A. W.; MacKinlay, A. C. 1997. The econometrics of financial markets. Princeton: Princeton University Press.

Campbell, J. Y.; Viceira, L. M. 2002. Strategic asset allocation: portfolio choice for long-term investors. Oxford: Oxford University Press. http://dx.doi. org/10.1093/0198296940.001.0001

Campbell, J. Y.; Viceira, L. M. 2005. The term structure of the risk: return trade-off, Financial Analysts Journal 61(1): 34-44. http://dx.doi.org/10.2469/faj. v61.n1.2682

Capozza, D. R.; Hendershott, P. H.; Mack, C. 2004. An anatomy of price dynamics in illiquid markets: analysis and evidence from local housing markets, Real Estate Economics 32(1): 1-32. http://dx.doi. org/10.1111/j.1080-8620.2004.00082.x

Capozza, D. R.; Seguin, P. J. 1996. Expectations, efficiency, and euphoria in the housing market, Regional Science and Urban Economics 26(3-4): 369-386. http://dx.doi.org/10.1016/0166-0462(95)02120-5

Case, K. E.; Shiller, R. J. 1989. The efficiency of the market for single-family homes, American Economic Review 79(1): 125-137.

Case, K. E.; Shiller, R. J. 1990. Forecasting prices and excess returns in the housing market, Journal of the American Real Estate \& Urban Economics Association 18(3): 253-273. http://dx.doi.org/10.1111/15406229.00521

Clapp, J. M.; Dolde, W.; Tirtiroglu, D. 1995. Imperfect information and investor inferences from housing price dynamics, Real Estate Economics 23(3): 239269. http://dx.doi.org/10.1111/1540-6229.00665

Collett, D.; Lizieri, C.; Ward, C. 2003. Timing and the holding periods of institutional real estate, Real Estate Economics 31(2): 205-222. http://dx.doi. org/10.1111/1540-6229.00063
Cutler, D. M.; Poterba, J. M.; Summers, L. H. 1990. Speculative dynamics and the role of feedback traders, American Economic Review 80(2): 63-68.

Daniel, K.; Hirshleifer, D.; Subrahmanyam, A. 1998. Investor psychology and security market under- and overreactions, The Journal of Finance 53(6): 18391885. http://dx.doi.org/10.1111/0022-1082.00077

De Bondt, Werner F. M.; Thaler, R. 1985. Does the stock market overreact?, Journal of Finance 40(3): 793-805. http://dx.doi.org/10.1111/j.1540-6261.1985. tb05004.x

DiPasquale, D.; Wheaton, W. C. 1994. Housing market dynamics and the future of housing prices, Journal of Urban Economics 35(1): 1-27. http://dx.doi. org/10.1006/juec.1994.1001

Englund, P.; Ioannides, Y. M. 1997. House price dynamics: an international empirical perspective, Journal of Housing Economics 6(2): 119-136. http://dx.doi. org/10.1006/jhec.1997.0210

Fama, E. F. 1991. Efficient capital markets: II, Journal of Finance 46(5): 1575-1617. http://dx.doi. org/10.1111/j.1540-6261.1991.tb04636.x

Fama, E. F.; French, K. R. 1988. Permanent and temporary components of stock prices, Journal of Political Economy 96(2): 246-273. http://dx.doi. org/10.1086/261535

Fraser, P.; Hoesli, M.; McAlevey, L. 2008. House prices and bubbles in New Zealand, Journal of Real Estate Finance and Economics 37(1): 71-91. http://dx.doi. org/10.1007/s11146-007-9060-8

Glaeser, E. L.; Gyourko, J. 2007. Housing dynamics. Harvard Institute of Economic Research, Discussion Paper 2137.

Glaeser, E. L.; Gyourko, J.; Saiz, A. 2008. Housing supply and housing bubbles, Journal of Urban Economics 64(2): 198-217. http://dx.doi.org/10.1016/j. jue.2008.07.007

Goodhart, C.; Hofmann, B. 2007. House prices and the macroeconomy: implications for banking and price stability. Oxford: Oxford University Press.

$\mathrm{Gu}$, A. Y. 2002. The predictability of house prices, Journal of Real Estate Research 24(3): 213-233.

Kim, J. H. 2006. Wild bootstrapping variance ratio tests, Economics Letters 92(1): 38-43. http://dx.doi. org/10.1016/j.econlet.2006.01.007

Liu, C. Y.; He, J. 1991. A variance-ratio test of random walks in foreign exchange rates, Journal of Finance 46(2): 773-785. http://dx.doi. org/10.1111/j.1540-6261.1991.tb02686.x

Lo, A. W.; MacKinlay, A. C. 1988. Stock market prices do not follow random walks: evidence from a simple specification test, Review of Financial Studies 1(1): 41-66. http://dx.doi.org/10.1093/rfs/1.1.41

Lo, A. W.; MacKinlay, A. C. 1989. The size and power of the variance ratio test in finite samples: a Monte Carlo investigation, Journal of Econometrics 40(2): 203238. http://dx.doi.org/10.1016/0304-4076(89)90083-3

Lynch, A. W.; Balduzzi, P. 2000. Predictability and transaction costs: the impact on rebalancing rules and behavior, Journal of Finance 55(5): 2285-2309. http://dx.doi.org/10.1111/0022-1082.00287 
MacKinnon, G. H.; Al Zaman, A. 2009. Real estate for the long term: the effect of return predictability on long-horizon allocations, Real Estate Economics 37(1): 117-153. http://dx.doi.org/10.1111/j.15406229.2009.00237.x

Malpezzi, S. 1999. A simple error correction model of house prices, Journal of Housing Economics 8(1): 27-62. http://dx.doi.org/10.1006/jhec.1999.0240

Mankiw, N. G.; Weil, D. N. 1989. The baby boom, the baby bust, and the housing market, Regional Science and Urban Economics 19(2): 235-258.

Meen, G. 2002. The time-series behavior of house prices: a transatlantic divide?, Journal of Housing Economics 11(1): 1-23. http://dx.doi.org/10.1006/ jhec.2001.0307

Merton, R. C. 1969. Lifetime portfolio selection under uncertainty: the continuous-time case, Review of Economics \& Statistics 51(3): 247-257. http://dx.doi. org/10.2307/1926560

Moskowitz, T. J.; Ooi, Y. H.; Pedersen, L. H. 2012. Time series momentum, Journal of Financial Economics 104(2): 228-250. http://dx.doi.org/10.1016/j.jfineco.2011.11.003

Oikarinen, E. 2006. The diffusion of housing price movements from center to surrounding areas, Journal of Housing Research 15(1): 3-28.

Oikarinen, E. 2009a. Household borrowing and metropolitan housing price dynamics - empirical evidence from Helsinki, Journal of Housing Economics 18(2): 126-139. http://dx.doi.org/10.1016/j.jhe.2009.04.001

Oikarinen, E. 2009b. Interaction between housing prices and household borrowing: the Finnish case, Journal of Banking \& Finance 33(4): 747-756. http://dx.doi. org/10.1016/j.jbankfin.2008.11.004
Poterba, J. M.; Summers, L. H. 1988. Mean reversion in stock prices: evidence and implications, Journal of Financial Economics 22(1): 27-59. http://dx.doi. org/10.1016/0304-405X(88)90021-9

Rehring, C. 2012. Real estate in a mixed-asset portfolio: the role of the investment horizon, Real Estate Economics 40(1): 65-95. http://dx.doi.org/10.1111/j.15406229.2011.00306.x

Røed Larsen, E.; Weum, S. 2008. Testing the efficiency of the Norwegian housing market, Journal of Urban Economics 64(2): 510-517. http://dx.doi.org/10.1016/j. jue.2008.05.004

Samuelson, P. A. 1969. Lifetime portfolio selection by dynamic stochastic programming, Review of Economics \& Statistics 51(3): 239-246. http://dx.doi. org/10.2307/1926559

Schindler, F. 2013. Predictability and persistence of the price movements of the S\&P/Case-Shiller house price indices, Journal of Real Estate Finance and Economics 46(1): 44-90. http://dx.doi.org/10.1007/s11146011-9316-1

Schindler, F. 2014. Predictability and persistence in UK house price movements, Journal of Real Estate Finance and Economics 48(1): 132-163. http://dx.doi. org/10.1007/s11146-012-9384-x

Shiller, R. J. 2003. From efficient markets theory to behavioral finance, Journal of Economic Perspectives 17(1): 83-104. http://dx.doi. org/10.1257/089533003321164967

Stracca, L. 2004. Behavioral finance and asset prices: where do we stand?, Journal of Economic Psychology 25(3): 373-405. http://dx.doi.org/10.1016/S01674870(03)00055-2 